\title{
СТРАТЕГИИ ВЗАИМОДЕЙСТВИЯ ТЕРРИТОРИАЛЬНЫХ СООБЩЕСТВ В ХОДЕ ГОРОДСКИХ КОНФЛИКТОВ (НА МАТЕРИАЛАХ ЭКСПЕРТНОГО ОПРОСА В КРУПНЫХ РЕГИОНАЛЬНЫХ ЦЕНТРАХ РФ)
}

В статье проводится анализ стратегий поведения в конфликте, конструктивных и деструктивных аспектов конфликтования, его институциальных рамок и возможностей интеграции территориальных сообществ в структуру принятия решений по проблемам городского развития. Методом исследования является экспертный опрос. Его география охватывает три центра субъектов РФ-Воронеж, Краснодар и Ярославль. Опрошено 34 эксперта, представляющих различные профессиональные группы (городские сообщества, некоммерческие организации и гражданские инициативы, органы власти регионального и местного уровня, бизнесструктуры, академическую среду). Теоретической рамкой исследования выступает подход, основанный на выделении основных стратегий поведения участников конфликтных ситуаций. По итогам проведенного исследования можно утверждать, что стратегии взаимодействия территориальных сообществ с другими субъектами городских конфликтов имеют, как правило, неконфронтационный характер. Чаще всего сообщества выбирают сотрудничество и компромисс, хотя такие стратегии не всегда оказываются эффективными. Это объясняется недостатком ресурсов для более активного отстаивания своих интересов. В структурах

Александра Викторовна Глухова- д. полит. н., профессор, заведующая кафедрой социологии и политологии, Воронежский государственный университет, Воронеж, Россия. Электронная почта: avglukhova@mail.ru

Алексей Иванович Кольба- д. полит. н., доцент, профессор кафедры государственной политики и государственного управления, Кубанский государственный университет, Краснодар, Россия. Электронная почта: alivka2000@mail.ru

Александр Владимирович Соколов- д. полит. н., доцент, заведующий кафедрой социально-политических теорий, Ярославский государственный университет, Ярославль, Россия. Электронная почта: alex8119@mail.ru 
конфликтующих сообществ обычно выделяется «ядро» активистов, но при этом велика и роль лидеров, осуществляюих значительную часть коммуникаций сообщества, определение стратегий, формирование повестки дня. Исследование показало, что городские сообщества остаются недостаточно встроенными в систему принятия политико-управленческих решений и институты публичной политики, что затрудняет и интеграцию городских сообществ в механизмы конструктивного регулирования конфликтов.

Ключевые слова: городские конфликты, городские территориальные сообщества, стратегии конфликтования, ресурсы

DOI: 10.17323/727-0634-2021-19-2-239-252

В современном научном и политическом дискурсах о городских конфликтах тематика территориальных сообществ занимает настолько значимое место, что обойти ее в данной сфере исследований практически невозможно. Сообщество такого типа представляет собой общность граждан, основанную на разделяемых ими интересах, привязанных к определенной части городского пространства (район города, микрорайон, иная территория). Большинство сюжетов и коллизий, сопровождающих процесс конфликтования-это истории, так или иначе связанные со становлением сообществ, их развитием, ростом, в некоторых случаяхс прекращением активности (Кольба, Кольба 2019). Вне активности сообществ большинство конфликтов в городском пространстве не актуализируется, в своем многообразии они являются необходимо (позитивно) конфликтными участниками жизни крупного города.

При этом репрезентации городских сообществ в рамках дискурсивного пространства неоднозначны. Если на начальном этапе исследований социальной жизни городов они рассматривались как «естественные экономические и культурные группировки» (Бёрджес 2015:28), то к настоящему времени сложилось множество интерпретаций данного явления (см.: Кольба 2020). Это связано как с изменениями в структуре городских отношений, вызванных ростом миграции, ускоренной застройкой новых, зачастую ранее не существовавших районов, появлением новых каналов и типов коммуникации и рядом других факторов, так и с различными фокусами анализа территориальных сообществ в качестве предмета исследования. Возможности сообществ оказывать влияние на различные стороны жизни города находятся в зависимости от институциальной среды, в рамках которой разворачивается их деятельность, а также от уровня организации самих сообществ, в частности, способности определять и осуществлять собственные стратегии участия в городских конфликтах.

Целью исследования является выявление стратегий взаимодействия территориальных сообществ в крупных региональных центрах современной 
России с другими субъектами социального пространства городов в процессе конфликтования.

\section{Концептуальные подходы к исследованию участия городских сообществ в конфликтах: краткий обзор}

К настоящему времени сложился ряд исследовательских подходов, в рамках которых участие городских сообществ в конфликтах рассматривается с различных методологических позиций. Весьма многочисленны исследования, использующие концепты, разработанные в ходе осмысления города как пространства гражданской и политической борьбы- «право на город» (Лефевр 2015; Харви 2008; Дроздова, Дроздова 2019), «Not in my back yard» (NIMBY) - «Только не на моём заднем дворе» (Einstein et al. 2019; Lea 2017) и др. В них конфликты с участием сообществ чаще всего интерпретируются как борьба за утверждение собственного видения городского пространства в качестве места для жизни и в противовес стремлению бизнеса или властей трансформировать его под собственные нужды.

Подход, в рамках которого конфликтные взаимодействия сообществ рассматриваются в парадигме «оспаривания городского пространства», применяется и исследователями петербургской школы (Тыканова 2017; Тыканова 2016). При этом в их работах значительное внимание уделяется гражданскому активизму и использованию политических и неполитических механизмов для реализации общественных интересов (Тыканова, Тенишева 2020; Желнина, Тыканова 2019; Тыканова, Хохлова 2017). В рамках этой исследовательской концепции рассматриваются как процессы развития и структурирования самих сообществ (формирование активистских «ядер», использование различных видов коммуникации, «эффект соседства» и др.), так и внешние стратегии и формы отношений с другими субъектами конфликта. Таким образом, данный ракурс исследований позволяет выявить «механику» городского конфликта в контексте их деятельности.

Концепт протестной мобилизации сообществ также создает перспективу изучения их участия в городских конфликтах. В центре внимания российских исследователей, развивающих данный подход, находятся такие проблемы, как методы действия протестных сообществ, их эффективность в условиях того или иного типа городского политического режима (Пустовойт 2018), «личностные траектории» развития участников протестов (Пустовойт 2019a), дискурсы протестующих и власти (Пустовойт 2019b), устойчивые конфигурации городских конфликтов, репертуар и адресаты протеста (Семенов 2019) и ряд других. Определенным ограничением для применения данного подхода является непопадание в фокус исследования конфликтующих сообществ, которые нельзя отнести к протестным.

Невелико число исследований, авторы которых опираются на подходы, сформированные в рамках классических теорий конфликта, хотя 
они представляются перспективными. К примеру, объяснительная модель, основанная на теории «стратегии конфликта» (Шеллинг 2016), позволяет описать конфликт горожан и застройщиков как проявление позиционной борьбы, связанной с издержками и уступками (Семенов и др. 2018). Применение конфликтологического подхода при изучении городских конфликтов нацелено на выявление возможностей их трансформации для раскрытия позитивного потенциала. Стратегии поведения субъектов конфликта рассматриваются здесь как инструмент рефлексивного управления конфликтами, а их эффективность оценивается исходя из того, в какой степени субъектам удается реализовать свои цели.

\section{Теоретико-методологические основы и методы исследования}

Исследование базируется на принципах конфликтной парадигмы изучения социальных и политических процессов, таких, как возможность управления конфликтами на основе их признания и регулирования, использование позитивно-функционального потенциала конфликтов для поддержания динамики политических процессов, необходимость диалога между властными институтами и структурами гражданского общества в процессе урегулирования конфликтов, развитие механизмов демократии как основы политической институциализации конфликтов. Данный подход позволяет выделить как деструктивные, так и конструктивные составляющие конфликтования, а также возможности интеграции сообществ в структуры принятия решений по поводу конфликта, интеракций с другими его акторами.

Для типологизации стратегий, реализуемых сообществами в конфликтах, использован подход, предложенный К. Томасом и Р. Кимлманном, основанный на выделении пяти основных стратегий: избегания, приспособления, конкуренции, компромисса и сотрудничества (Thomas, Kilmann, 1974). Критериями типологизации являются ориентация в ходе конфликта на собственные интересы либо на интересы других участников. Они предполагают, соответственно, уход от конфликта; принятие требований оппонента; стремление к достижению цели, не считаясь с оппонентами; соглашение на основе взаимных уступок; совместные действия для решения проблемы, вызвавшей конфликт.

Для получения эмпирических данных мы использовали метод структурированного экспертного опроса, проведенного в трех городах России: Воронеже, Краснодаре, Ярославле (2020 г.). Основанием для выбора городов в качестве поля исследований послужило наличие следующих факторов: они являются крупными, активно развивающимися региональными центрами, находятся в разных федеральных округах, отличаются высоким уровнем активности территориальных сообществ и интенсивностью городских конфликтов. Нами опрошено 34 эксперта, представляющих городские 
сообщества, некоммерческие организации и гражданские инициативы, органы власти регионального и местного уровня, бизнес-структуры, академическую среду. Все эксперты имеют опыт участия в городских конфликтах либо их исследования. В Ярославле опрошено 13 экспертов, в Воронежедесять, в Краснодаре- 11. Таким образом осуществлен охват всех ключевых экспертных групп по данной тематике, что позволяет говорить о валидности собранных данных как в целом по выборке, так и по отдельным городам.

Тематика и блоки вопросов разработаны на основе выводов по итогам первого этапа исследования, проведенного в 2019 г. в тех же городах (по четыре-пять полуструктурированных интервью с лидерами и активистами городских сообществ) (Кольба, Кольба 2020). При анализе данных экспертного опроса использовалось «правило большинства»: для интерпретации выбираются те оценки, которых придерживается большинство экспертов (при учете в необходимых случаях данных, поддержанных значительным числом экспертов, не составляющим большинства).

\section{Стратегии взаимодействия}

\section{с другими участниками конфликтов}

Для успешного решения поставленных задач городские сообщества должны взаимодействовать с другими субъектами конфликтов. Важность данной деятельности отмечается большинством экспертов (более половины), утверждающим, что отказ от взаимодействия с органами власти, бизнесом и другими сообществами непродуктивен. Это вполне коррелирует с положениями теории конфликта: выбор стратегии избегания влечет за собой неучастие в решении проблемы.

Сравнивая обращения через официальные (письма, петиции, обращения) и неофициальные (личные знакомства, общение в социальных сетях) каналы коммуникации, эксперты отмечали, что вторые используются чаще первых. Причем, если официальные каналы коммуникации преимущественно задействуются во взаимодействии с государственными органами власти и бизнесом, то неофициальное взаимодействие свойственно контактам с другими сообществами и с представителями органов муниципальной власти.

Теоретически более прочными коммуникации становятся при создании коалиций субъектов, имеющих общие интересы в конфликте. Эксперты отмечают, что коалиции для решения конкретных проблем совместно с другими субъектами возникают намного чаще, чем постоянные. Помимо этого, сообщества преимущественно вступают в коалиции между собой, а также изредка с представителями бизнеса и муниципальной власти.

Распространено использование такого механизма, как участие сообществ в консультациях с органами власти. Создаваемые совместно властью и сообществами площадки, такие, как общественные советы, выглядят более привлекательным форматом взаимодействия, т.к. сущес- 
твуют автономно и в более свободной форме, чем связанные исключительно с органами власти.

Через вышеперечисленные каналы и методы коммуникации реализуется конструктивное двухстороннее взаимодействие между сообществами, властью и бизнесом, в то время как два иных метода: давление через публичные каналы коммуникации (СМИ, Интернет, социальные сети) и давление через систему государственного управления (обращения в вышестоящие органы и т.д.) являются в большей степени односторонними. Эксперты отмечают, что сообщества намного реже используют публичные каналы коммуникации, чем обращения к государственным органам. Это приводит к тому, что в большинстве случаев давление, в особенности на муниципальные органы власти и бизнес, происходит через органы государственной власти и иные контролирующие и надзорные органы, что косвенно свидетельствует о недостатке собственных ресурсов для влияния на принятие решений, необходимость апеллировать к субъектам, наделенным властными полномочиями. Показательно согласие большинства экспертов относительно того, что сообщества редко оказывают давление друг на друга, демонстрируя определенную солидарность.

Значимой проблемой представляется распространенность использования тех или иных стратегий в отношении различных субъектов городских конфликтов. Наиболее часто встречающейся, по мнению экспертов, является стратегия сотрудничества. Она чаще всего применяется в отношении других сообществ, в меньшей степени для бизнеса и муниципальной власти и редко с органами региональной власти. Стратегия компромисса чаще всего используется в отношении органов власти, реже для бизнеса и других сообществ. Уход от конфликта-третья по частоте применения стратегия, чаще используемая в отношении органов региональной власти и бизнеса. Стратегия конкуренции выбирается городскими сообществами при взаимодействии с бизнесом. Наименее используемая стратегия, по мнению экспертов,- приспособление, она чаще всего используется в отношении органов региональной власти. Мнение экспертов в данном случае можно объяснить тем, что на уровне регионов принимаются нормативно-правовые акты по регулированию деятельности и поддержке некоммерческих организаций и гражданских инициатив.

Если же говорить об эффективности представленных выше стратегий, то она во многом соответствует частоте использования. По мнению большей части экспертов, наиболее эффективно себя показывает стратегия сотрудничества между различными сообществами, а также стратегия сотрудничества сообществ и органов муниципальной власти. Сотрудничество с бизнес-структурами не распространено, в отличие от компромисса и уступок. Об этом косвенно свидетельствует и относительно низкий уровень успешности применения стратегии конкуренции в отношениях с девелоперами, продолжающими осуществлять застройку городов без выполнения социальных и экологических обязательств (что особенно характерно для 
Краснодара). Обращает на себя внимание тот факт, что в ответах на вопрос о наиболее характерных стратегиях взаимодействия городских сообществ с другими субъектами городских конфликтов компромисс упоминается сравнительно редко, а в ответах на вопрос об эффективности встречается чаще. Возможно, эксперты отреагировали на этот вопрос в нормативном ключе, а не по факту реальной эффективности компромиссной стратегии.

Помимо этого, эксперты отметили ряд причин, по которым сообщества не выбирают наиболее эффективные поведенческие стратегии. Так, во взаимодействии с органами муниципальной и региональной власти у них недостаточно опыта и ресурсов для привлечения к себе внимания. Помимо этого, эксперты отмечают отсутствие желания взаимодействовать с органами власти у сообществ, которые не верят в результативность совместной работы. По поводу муниципальных органов власти высказывалось мнение, что они «вообще не субъектны сейчас, там не с кем и не о чем разговаривать» (лидер городского сообщества, Воронеж). В региональных структурах власти чиновники, ответственные за внутреннюю политику, «претендуют маркировать только «спокойных» активистов, с которыми они готовы работать» (лидер городского сообщества, Воронеж). В то же время эксперты, представляющие властные структуры, упоминали о неспособности сообществ идти на компромисс с муниципальными и региональными органами власти (муниципальный чиновник, Краснодар). Если же говорить про бизнес, эксперты также указывают на отсутствие опыта коммуникации, упоминают отсутствие интереса со стороны предпринимателей. Отмечают принципиальное нежелание ряда сообществ разделять зоны влияния и взаимодействовать в принципе, разобщенность и конкуренцию между ними (региональные и муниципальные чиновники во всех трех городах).

Таким образом, в большинстве случаев городские сообщества демонстрируют склонность использовать неконфронтационные стратегии взаимодействия с другими участниками конфликтов. В то же время нет ярко выраженной тенденции использования пассивных стратегий-ухода и приспособления. На наш взгляд, подобное положение вещей отражает разрыв между стремлением сообществ влиять на развитие городского пространства и отстаивать свои интересы в нем и необходимой для этого ресурсной базой.

\section{Роль лидеров и активистов городских сообществ в формировании стратегий и их влияние на городское пространство}

Наиболее значимыми ресурсами, позволяющими лидерам и активистам городских сообществ оказывать влияние на разрешение конфликтных ситуаций, по мнению экспертов, являются: широкая поддержка со стороны сообщества, большое количество сторонников; наличие общественного статуса (известность, популярность в городе, членство/лидерство в обще- 
ственной организации и т.д.); умение вести переговоры, создавать коалиции, привлекать сторонников, убеждать оппонентов. Помимо этого, значимыми можно считать неформальные связи с представителями властных элит и возможность привлечения административного ресурса для разрешения конфликтов.

Наиболее целесообразным форматом лидерства, по мнению экспертов, для сообщества является формирование «ядра» активистов, между которыми разделяются функции управления. Менее эффективными и распространенными вариантами эксперты назвали наличие одного лидера или двух-трех. Большинство считает, что сообществ без лидеров не существует. Однако есть и противоположные мнения, авторы которых приводят в пример движения экологов, обманутых дольщиков. Данное мнение, наш взгляд, отражает большую выраженность сетевых взаимодействий в этих сообществах, не имеющих строго территориальной привязки.

Экспертам также предложено оценить по десятибалльной шкале значимость иных функций лидера для управления сообществом в условиях конфликта и поддержания его сплоченности. Наиболее значимыми функциями являются обеспечение контактов сообщества с органами власти, бизнесструктурами, другими акторами городской политики (9,5 баллов по шкале от 0 до 10), а также определение тактики поведения в конфликтных ситуациях $(8,4)$, представление интересов сообщества в публичном пространстве $(8,1)$, формирование повестки дня, актуализации проблем, значимых для сообщества $(7,9)$. Высокие оценки ряда функций подтверждают значимость лидеров в ситуации городского конфликта. Следует отметить, что летом-осенью 2020 г. наблюдается рост участия гражданских активистов в избирательных кампаниях, как в качестве независимых, так и партийных кандидатов, что может привести к росту их влияния в масштабах сообществ.

Чуть больше половины считает, что главной целью деятельности городских сообществ является решение проблем в рамках конкретных городских территорий. Половина экспертов уверена, что, помимо этого, объединения должны в той же степени решать проблемы общегородского характера, а также продвигать лидеров и активистов в муниципальные структуры власти, дающие возможность влиять на городскую политику. Стоит заметить, что ни один эксперт не выбрал приоритетной целью участие в публичной политике. При этом для достижения целей деятельности городские сообщества, по мнению большинства экспертов, должны иметь «двухуровневую» систему организации, объединяющую территориальные сообщества и общегородских гражданских лидеров.

Для того чтобы конкретизировать мнения экспертов задавался вопрос о реальной роли сообществ в управлении конфликтами. Так, большинство экспертов согласилось с тем, что городские сообщества могут оказывать существенное влияние на конфликты, но у них недостаточно ресурсов, чтобы реализовывать свои цели на постоянной основе. Это подтверждает 
слабость ресурсной базы сообществ на нынешнем этапе развития. Таким образом, мы можем говорить о значительной роли сообществ, однако должны учитывать тот факт, что ряд экспертов указывали на необходимость получения поддержки сообществам со стороны более влиятельных субъектов, например, органов власти или бизнеса.

\section{Заключение}

Полученные данные позволяют сделать вывод о том, что стратегии конфликтования городских сообществ публичном пространстве городской политики определяются, исходя из совокупности внутренних и внешних факторов. К числу первых относятся наличие ресурсной базы и ярко выраженных лидеров, внутренней структуры сообщества (экологи и обманутые дольщики демонстрируют способность добиваться значимых результатов за счет сетевых связей). Во второй группе факторов выделяется специфика субъектов, выступающих в качестве оппонентов в конфликте. Способность сообществ реализовывать определенную стратегию повышает их роль в определении «повестки дня» городского развития, а также увеличивает мобилизационные возможности.

Преобладание стратегий, ориентированных на практики конструктивного взаимодействия, минимизация конкуренции, приспособления, ухода от конфликта дает возможность сделать вывод об их ориентации на диалоговый формат урегулирования конфликтов. В то же время это может быть следствием недостаточной обеспеченности сообществ ресурсами для более активных действий в отстаивании своих позиций, на что прямо указывает большинство экспертов. Можно сказать, что им пока не удается скорректировать «общественный договор» на городском и региональном уровне, чему в том числе препятствует мягкость стратегий конфликтования. Настороженное отношение региональных и местных органов власти к гражданской активности в этой сфере не создает предпосылок для быстрого продвижения городских сообществ в политику. При том декларируемое многими экспертами «отсутствие опыта», «неумение идти на компромисс», «разобщенность сообществ» являются маркерами недостаточной готовности использовать политические механизмы и включаться в соответствующие практики, что могло бы способствовать развитию ресурсной базы. На это указывает и относительная неразвитость сотрудничества с политическими партиями и движениями.

Возможно, полученный опыт участия в политике (в роли кандидатов на муниципальных выборах, избранных депутатов) приведет к некоторому смещению акцентов деятельности представляемых ими сообществ, использованию более активных стратегий в конфликтах, так как роль лидеров в их функционировании достаточно велика. Лидеры являются значимым элементом в структуре сообществ, имеющих территориальный характер, и могут способствовать его выходу на общегородской уровень (а «двухуровневые» 
сообщества дают шанс вынести локальную проблему в общегородскую повестку, а также более активно использовать политические методы решения проблем). Кроме того, сообщества такого типа потенциально могут выступать в роли «социальных лифтов» для общественных активистов. Немаловажно и то, что лидеры сообществ несут основную нагрузку по поддержанию конструктивных коммуникаций с оппонентами, что обеспечивает развитие сценариев конфликтов, не переходящих в острую конфронтацию.

В целом проведенное исследование показало, что сообщества развиваются как субъекты конфликтов, способные рационально формировать и реализовывать определенные стратегии, но при этом продолжают испытывать сложности институциального и ресурсного характера. Рост их влияния на решение городских проблем лимитируется также системными факторами, т.е. теми ограничениями, которые создает формат политических процессов. В частности, сужены возможности для создания эффективных переговорных площадок, позволяющих внедрить механизмы коллаборативного планирования. Ни представительные органы власти региональных центров, ни их общественные палаты, ни общественные советы при органах власти по разным причинам в полной мере таких функций не выполняют. Это затрудняет и интеграцию городских сообществ в механизмы принятия решений по поводу конфликтов в городском пространстве.

\section{Выражение признательности}

Исследование выполнено при финансовой поддержке РФФИ в рамках научного проекта № 19-011-00571 «Конфликты в процессе функционирования городских сообществ крупных региональных центров России: концептуальные основания исследования и политические методы снижения деструктивного потенциала».

Редакция благодарит программу «Университетское партнерство» за поддержку и возможность опубликовать данную статью.

\section{Список источников}

Бёрджес Э. У. (2015) Рост города: введение в исследовательский проект. Д. В. Ефременко (ред.) Чикагская школа сочиологии: сборник переводов. М.: ИНИОН РАН: 20-34.

Дроздова А.А., Дроздова Ю.А. (2019) Концептуализация городского сообщества в публичном пространстве современного города. Вопросы управления. Доступно по ссылке: http://journal-management.com/issue/2020/01/06 (дата обращения: 15 октября 2020).

Желнина А. А., Тыканова Е. В. (2019) Формальные и неформальные гражданские инфраструктуры: современные исследования городского локального активизма в России. Журнал сочиологии и сочиальной антропологии, (1): 63-84.

Кольба А.И. (2020) Конфликты в процессе функционирования городских сообществ: современное состояние исследований. Социальные и гуманитарные знания, 6 (1): 20-29.

Кольба А. И., Кольба Н. В. (2019) Городские конфликты как фактор гражданско-политической активизации локальных сообществ. Политическая наука, (2): 160-179.

Кольба А.И., Кольба Н.В. (2020) Структура, модели и стратегии участия городских сообществ в конфликтах. Конфликтология, 15 (2):54-67. 
Лефевр А. (2015) Производство пространства. М.: Strelka Press.

Медведев И.Р. (2017) Разрешение городских конфликтов. М.: Инфотропик.

Пустовойт Ю.А. (2018) «Земля» и «воля»: городские режимы и протестные сообщества в сибирских городах. Власть и элиты, (5):295-330.

Пустовойт Ю.А. (2019а) Личная история как основа формирования протестных сообществ (по материалам исследования сибирских городов). Траектории политического развития России: институты, проекты, акторы. Москва: МГПУ.

Пустовойт Ю.А. (2019b) Мобилизация, городской режим и протесты: опыт трансактного анализа дискурса власти и протестных сообществ в сибирских городах. Развитие территорий, 1 (15): 614.

Разинский Г.В. (2018) Муниципальная власть и местные сообщества: пути оптимизации отношений. Вестник Пермского национального исследовательского политехнического университета. Социально-экономические науки, (3): 162-173.

Семенов А. В. (2019) Корни травы: паттерны низовой городской мобилизации в России. Социологические исследования, (12):29-37.

Семенов А. В., Шевцова И.К., Бедерсон В. Д. (2018) Городская мобилизация и градостроительная политика: стратегическое взаимодействие местных жителей и застройщиков в ситуации конфликта. Журнал соџиологии и социальной антропологии, 21 (3): $140-169$.

Тыканова Е.В. (2016) Консолидация локальных сообществ в ситуации оспаривания городского пространства Санкт-Петербурга. Петербургская социология сегодня, (7):364-388.

Тыканова Е. В. (2017) Город как территория неравенства: оспаривание сноса гаражных строений в Санкт-Петербурге. Петербургская соииология сегодня, (8): 54-72.

Тыканова Е.В., Хохлова А. М. (2017) Между политическим и аполитичным: формы участия локальных сообществ в защите городских территорий. Современный город: власть, управление, экономика. Пермь: ПНИПУ:218-236.

Тыканова Е.В., Тенишева К.А. (2020) В плену «эффекта соседства»: социальный капитал и активизм в новых анклавных жилищных комплексах. Журнал социологии и социальной антропологии, 23 (2): 7-35.

Харви Д. (2008) Право на город. Логос, (3): 80-94.

Шеллинг Т. (2016) Стратегия конфликта. Москва: ИРИСЭН, Социум.

Einstein K., Glick D., Palmer M. (2019) Neighborhood Defenders: Participatory Politics and America's Housing Crisis. Cambridge: Cambridge University Press.

Gunton T., Day J.C. (2003) The Theory and Practice of Collaborative Planning in Resource and Environmental Management. Environments, (31): 5-19.

Lea S. (2017) From NIMBY to Enlightened Resistance: A Framework Proposal to Decrypt Landuse Disputes Based on a Landfill Opposition Case in France. Local Environment, 22 (4):461-477.

McAuliffe C., Rogers D. (2019) The Politics of Value in Urban Development: Valuing Conflict in Agonistic Pluralism. Planning Theory, 18 (3):300-318.

Thomas K., Kilmann R. (1974) The Thomas-Kilmann Conflict Mode Instrument. Mountain View, CA: CPP.

Ward K., Imbroscio D., Martin D., Stone C., Whelan R., Miraftab F., Cochrane A. (2011) Urban Politics: An Interdisciplinary Dialogue. International Journal of Urban and Regional Research, 35(4): 853-871. 
Aleksandra Gluhova, Alexey Kolba, Aleksandr Sokolov

\section{STRATEGIES OF URBAN COMMUNITIES IN CONFLICT PROCESSES (A CASE STUDY OF RUSSIA'S LARGE REGIONAL CENTERS)}

This article analyses behaviour strategies during conflict, including constructive and destructive aspects, institutional frameworks and considers the possibility of integrating territorial communities into decision-making systems in urban development. The research was based on an expert survey. Its geography covers three regional centers of the Russian Federation: Voronezh, Krasnodar and Yaroslavl. In total, thirty-four experts were interviewed representing various professional groups (urban communities, non-profit organizations and civil initiatives, regional and the local authorities, business structures, and academia). The theoretical basis of the research is the approach, which identified the main strategies of behaviour of participants in conflict situations. Based on the results of the study, it can be argued that the main prerequisites for the creation of communities are territorial identity and the presence of specific problems in a certain territory. Strategies of interaction with other subjects of urban conflicts are, as a rule, non-confrontational in nature. More often than not, communities choose cooperation and compromise, although such strategies are not always effective. This is due to the lack of resources to more actively defend their interests. In the structures of conflicting communities, a 'core' of activists is usually distinguished, but the leader's role is also great. Through the latter, a significant part of the community's communications is carried out, the definition of strategies, the formation of the agenda. The study shows that urban communities remain insufficiently integrated into the system of political and administrative decision-making and public policy institutions, which also complicates the integration of urban communities into mechanisms for constructive conflict regulation.

Key words: urban conflicts, urban territorial communities, conflict strategies, resources

DOI: 10.17323/727-0634-2021-19-2-239-252

Aleksandra Gluhova - Dr. Sci. (Polit.), Professor, Head of the Department of Sociology and Political Science, Voronezh State University, Voronezh, Russian Federation. Email: avglukhova@mail.ru

Alexey Kolba - Dr. Sci. (Polit.), Associate Professor, Department of State Policy and Public Administration, Kuban State University, Krasnodar, Russian Federation. Email: alivka2000@mail.ru

Aleksandr Sokolov- Dr. Sci. (Polit.), Associate Professor, Head of the Department of Social and Political Theories of the Yaroslavl' State University, Yaroslavl', Russian Federation. Email: alex8119@mail.ru 


\section{References}

Burgess E. W. (2015) Rost goroda: vvedenie v issledovatel'skiy proekt [City Growth: An Introduction to the Research Project]. In: D. V. Efremenko (ed.) Chikagskaya shkola sotsiologii: sbornik perevodov [Chicago School of Sociology: A Collection of Translations]. M.: INION RAN:20-34.

Drozdova A.A., Drozdova Yu.A. (2019) Kontseptualizatsiya gorodskogo soobshchestva v publichnom prostranstve sovremennogo goroda [Conceptualization of the Urban Community in the Public Space of a Modern City]. Voprosy upravleniya [Management Issues]. Available at: http://journal-management.com/issue/2020/01/06 (accessed 15 October 2020).

Einstein K., Glick D., Palmer M. (2019) Neighborhood Defenders: Participatory Politics and America's Housing Crisis. Cambridge: Cambridge University Press.

Gunton T., Day J.C. (2003) The Theory and Practice of Collaborative Planning in Resource and Environmental Management. Environments, (31):5-19.

Harvey D. (2008) Pravo na gorod [The Right to the City]. Logos, (3): 80-94.

Kolba A. I. (2020) Konflikty v processe funkcionirovanija gorodskih soobshhestv: sovremennoe sostojanie issledovanij [Conflicts in the Functioning Process Urban Communities: Current State of Research]. Social'nye i gumanitarnye znanija [Social and Humanitarian Knowledge], 6 (1):20-29.

Kolba A.I., Kolba N. V. (2019) Gorodskie konflikty kak faktor grazhdansko-politicheskoj aktivizacii lokal'nyh soobshhestv [Urban Conflicts as a Factor of the Local Communities' Civil-Political Activation]. Politicheskaja nauka [Political Science], (2): 160-179.

Kolba A.I., Kolba N. V. (2020) Struktura, modeli i strategii uchastija gorodskih soobshhestv v konfliktah [Structure, Models and Strategies of Participation of Urban Communities in Conflicts]. Konfliktologija [Conflictology], 15 (2): 54-67.

Lea S. (2017) From NIMBY to Enlightened Resistance: A Framework Proposal to Decrypt Landuse Disputes Based on a Landfill Opposition Case in France. Local Environment, 22 (4): 461-477.

Lefebvre H. (2015) Proizvodstvo prostranstva [The Production of Space]. M.: Strelka Press.

McAuliffe C., Rogers D. (2019) The Politics of Value in Urban Development: Valuing Conflict in Agonistic Pluralism. Planning Theory, 18 (3):300-318.

Medvedev I. R. (2017) Razreshenie gorodskikh konfliktov [Resolution of Urban Conflicts]. M.: Infotropik.

Pustovoyt Yu.A. (2018) 'Zemlya' i 'volya': gorodskie rezhimy i protestnye soobshchestva v sibirskikh gorodakh [Land and Freedom: Urban Regimes and Protest Communities in Siberian Cities]. Vlast' $i$ elity [Power and Elites], (5): 295-330.

Pustovoyt Yu.A. (2019a) Lichnaya istoriya kak osnova formirovaniya protestnykh soobshchestv (po materialam issledovaniya sibirskikh gorodov) [Personal History as the Basis for the Formation of Protest Communities (Based on Materials from a Study of Siberian Cities)]. Traektorii politicheskogo razvitiya Rossii: instituty, proekty, aktory [Trajectories of Russia's Political Development: Institutions, Projects, Actors]. Moscow: MPGU. 
Pustovoyt Yu.A. (2019b) Mobilizatsiya, gorodskoy rezhim i protesty: opyt transaktnogo analiza diskursa vlasti i protestnykh soobshchestv v sibirskikh gorodakh [Mobilization, Urban Regime and Protests: Experience of Transactional Analysis of the Discourse of Power and Protest Communities in Siberian Cities]. Razvitie territoriy [Territory Development], 1 (15): 6-14.

Razinskiy G. V. (2018) Munitsipal'naya vlast' i mestnye soobshchestva: puti optimizatsii otnosheniy [Municipal Authorities and Local Communities: Ways of Optimizing Relations]. Vestnik Permskogo natsional'nogo issledovatel'skogo politekhnicheskogo universiteta. Sotsial'noekonomicheskie nauki [PNRPU Sociology and Economics Bulletin], (3): 162-173.

Schelling T. (2016) Strategiya konflikta [Conflict Strategy]. Moscow: IRISEN, Sotsium.

Semenov A. V. (2019) Korni travy: patterny nizovoy gorodskoy mobilizatsii v Rossii [The Roots of the Grass: Patterns of Grassroots Urban Mobilization in Russia]. Sotsiologicheskie issledovaniya [Sociological Studies], (12):29-37.

Semenov A.V., Shevtsova I.K., Bederson V.D. (2018) Gorodskaya mobilizatsiya i gradostroitel'naya politika: strategicheskoe vzaimodeystvie mestnykh zhiteley i zastroyshchikov v situatsii konflikta [Urban Mobilization and Urban Development: Strategic Interactions between Residents and Developers in a Conflict]. Zhurnal sotsiologii $i$ sotsial'noy antropologii [The Journal of Sociology and Social Anthropology], 21 (3): 140-169.

Thomas K., Kilmann R. (1974) The Thomas-Kilmann Conflict Mode Instrument. Mountain View, CA: CPP.

Tykanova E. V. (2016) Konsolidatsiya lokal'nykh soobshchestv v situatsii osparivaniya gorodskogo prostranstva Sankt-Peterburga [Consolidation of Local Communities in the Situation of Challenging the Urban Space of St. Petersburg]. Peterburgskaya sotsiologiya segodnya [Petersburg Sociology Today], (7):364-388.

Tykanova E. V. (2017) Gorod kak territoriya neravenstva: osparivanie snosa garazhnykh stroeniy v Sankt-Peterburge [The City as a Territory of Inequality: Challenging the Demolition of Garage Buildings in St. Petersburg]. Peterburgskaya sotsiologiya segodnya [Petersburg Sociology Today], (8): 54-72.

Tykanova E. V., Khokhlova A.M. (2017) Mezhdu politicheskim i apolitichnym: formy uchastiya lokal'nykh soobshchestv v zashchite gorodskikh territoriy [Between the Political and the Apolitical: Forms of Participation of Local Communities in the Protection of Urban Areas]. Sovremennyy gorod: vlast', upravlenie, ekonomika [Modern City: Power, Management, Economy]. Perm': PNIPU:218-236.

Tykanova E. V., Tenisheva K.A. (2020) V plenu 'effekta sosedstva': sotsial'nyy kapital i aktivizm v novykh anklavnykh zhilishchnykh kompleksakh [Trapped by the 'Neighborhood Effect': Social Capital and Activism in the New Enclave Condominiums]. Zhurnal sotsiologii i sotsial'noy antropologii [The Journal of Sociology and Social Anthropology], 23 (2): $7-35$.

Ward K., Imbroscio D., Martin D., Stone C., Whelan R., Miraftab F., Cochrane A. (2011) Urban Politics: An Interdisciplinary Dialogue. International Journal of Urban and Regional Research, 35(4): 853-871.

Zhelnina A.A., Tykanova E. V. (2019) Formal'nye i neformal'nye grazhdanskie infrastruktury: sovremennye issledovaniya gorodskogo lokal'nogo aktivizma v Rossii [Formal and Informal Civic Infrastructure: Contemporary Studies of Urban Local Activism in Russia]. Zhurnal sotsiologii i sotsialnoy antropologii [The Journal of Sociology and Social Anthropology], 22 (1): 162-192. 